www.jmscr.igmpublication.org

Impact Factor 5.84

Index Copernicus Value: 83.27

ISSN (e)-2347-176x ISSN (p) 2455-0450

crossref DOI: _https://dx.doi.org/10.18535/jmscr/v5i2.119

Journal Of Medical Science And Clinical Research

\title{
Comparison of Intranasal Dexmedetomidine and Oral Midazolam for Premedication in Pediatric Anaesthesia - A Randomized Controlled Trial
}

\author{
Authors \\ Jamuna Rani $\mathbf{J}^{\mathbf{1}}$, Sheeila Rani Imanual ${ }^{2}$, Unnikrishnan $\mathbf{G}^{3 *}$ \\ ${ }^{1}$ Assistant Professor, Dept of Anaesthesia Government Medical College Thiruvananthapuram Kerala India \\ ${ }^{2}$ Associate Professor, Dept of Anaesthesia Government Medical College Thiruvananthapuram Kerala India \\ ${ }^{3}$ Assistant Professor, Dept of General Surgery, Govt Medical College Thiruvananthapuram Kerala India \\ Corresponding Author* \\ Unnikrishnan G
}

Assistant Professor, Dept of General Surgery

Govt Medical College Thiruvananthapuram, Kerala, India.

Email: unni_ukg@rediffmail.com.Phone:+919961794443

\begin{abstract}
Introduction: Minimizing distress for children in the operating room $(O R)$ environment and to facilitate a smooth induction of anaesthesia is one of the challenges for pediatric anesthesiologists. Midazolam is the most commonly used drug. Dexmedetomidine (22) is a newer $\alpha 2$-agonist with a more selective action on the $\alpha$ 2-adrenoceptor and a shorter half-life. Its bioavailability is $81.8 \%$ (72.6-92.1\%) when administered via the buccal mucosa. Our aim of the study was primarily to compare the efficacy of intranasal dexmedetomidine and oral midazolam for preoperative anxiolysis and sedation in children before induction of anaesthesia and Secondary objective was to compare the hemodynamic changes-Systolic blood pressure and heart rate changes, wake-up behavior, time until ready for discharge from the PACU between the two groups.

Materials and Methods: Study was conducted at the Department of Pediatric Surgery and Department of Anesthesiology, SAT hospital Thiruvananthapuram during the period 2014 - 2015.Inclusion criteria : ASAI \& 11, Children in the age group 4-12years, Duration of surgery $<2 \mathrm{hrs}$, Elective surgery were included. Exclusion Criteria: Allergy or hypersensitive reaction to dexmedetomidine or midazolam, ASA III \& IV, Age $<$ 4years, Full stomach, Duration of surgery > 2hrs, Emergency surgery were excluded. Patients were divided into those receiving intranasal dexmedetomidine and those receiving oral midazolam. Children are randomly allocated to one of the two groups.

Observation and Results: Children premedicated with $1 \mu \mathrm{g} / \mathrm{kg}$ of intranasal dexmedetomidine attained more significant and satisfactory sedation at parental separation and at induction of anaesthesia than those patients who received oral midazolam.

Conclusion: In this study, we have shown that $1 \mathrm{ng} / \mathrm{kg}$ intranasal dexmedetomidine is another technique for producing sedation in children and it causes no discomfort during administration. Intranasal drug administration is relatively quick, simple, and may have benefits over transmucosal routes or rectal administration, which requires more patient cooperation.
\end{abstract}




\section{Introduction}

One of the challenges for pediatric anaesthesiologists is to minimize distress for children in the operating room (OR) environment and to facilitate a smooth induction of anaesthesia. This is often accomplished by prior administration of a sedative drug before transfer to the $\mathrm{OR}^{(1)}$. Midazolam is the most commonly used drug for this purpose ${ }^{(2)}$. Premedication with midazolam has shown to be more effective than parental presence ${ }^{(3)}$ or placebo in reducing anxiety and improving compliance at induction of anaesthesia ${ }^{(4)}$. The beneficial effects of midazolam include sedation, anxiolysis, and reduction of postoperative vomiting. A recent evidence-based clinical update has shown that oral midazolam $^{(5)} 0.5 \mathrm{mg} / \mathrm{kg}$ is effective in reducing both separation and induction anxiety in children, with minimal effect on recovery time. However, the acceptability of oral midazolam by pediatric patients is only $70 \%$. Other undesirable effects including restlessness, paradoxical reaction, and negative postoperative behavioral changes have made it a less than ideal premedication ${ }^{(8,12)}$. Although amnesia is considered an advantage by some authorities, it has also been regarded as a possible disadvantage by others ${ }^{(15)}$. Clonidine ${ }^{(16)}$, an $\alpha 2$-agonist, has been suggested as another option for premedication in children and previous studies have shown it to be equally as effective as midazolam. Oral ${ }^{(17,18)}$ clonidine premedication has also been shown to reduce the incidence of sevoflurane induced emergence agitation. Dexmedetomidine $^{(22)}$ is a newer $\alpha 2$-agonist with a more selective action on the a2-adrenoceptor and a shorter half-life ${ }^{(35)}$. Its bioavailability is $81.8 \%$ (72.6-92.1\%) when administered via the buccal mucosa. Yuen et $\mathrm{al}^{(22)}$, in a randomized, crossover evaluation of healthy adult volunteers, demonstrated that intranasal 1 and $1.5 \mu \mathrm{g} / \mathrm{kg}$ dexmedetomidine produces sedation in 45-60 min and peaks in 90-105 min. In addition, they observed only a modest reduction of heart rate (HR) and arterial blood pressure (BP). The purpose of this investigation was to test the hypothesis that intranasal dexmedetomidine is as effective as oral midazolam for preoperative anxiolysis and sedation in children before induction of anaesthesia. Our aim of the study was primarily to compare the efficacy of intranasal dexmedetomidine and oral midazolam for preoperative anxiolysis and sedation in children before induction of anaesthesia and Secondary objective was To compare the hemodynamic changes-Systolic blood pressure and heart rate changes, wake-up behavior, time until ready for discharge from the PACU between the two groups.

\section{Materials and Methods}

Approval from the ethical committee was obtained prior to the start of the study. Our Study Design was Randomized controlled study. Study was conducted at the Department of Pediatric Surgery and Department of Anesthesiology, SAT hospital Thiruvananthapuram during the period 2014 - 2015. Study population includes all children who received intranasal Dexmedetomidine and oral midazolam for premedication during the study period.

Inclusion criteria: ASA I \& II, Children in the age group 4-12years, Duration of surgery $<2 \mathrm{hrs}$, Elective surgery were included. Exclusion Criteria: Allergy or hypersensitive reaction to dexmedetomidine or midazolam, ASA III \& IV , Age < 4years, Full stomach, Duration of surgery > $2 \mathrm{hrs}$, Emergency surgery were excluded.

Sample size is estimated using the software EPI 6

$$
\mathbf{n}=\boldsymbol{Z}_{\alpha_{1 / 2}} \boldsymbol{\beta} \times \mathrm{P}_{1}\left(100-\mathrm{P}_{1}\right)+\mathbf{P}_{2}\left(100-\mathrm{P}_{2} /\left(\mathrm{P}_{1}-\mathrm{P}_{2}\right)^{2}\right.
$$

The proportion of sedation according to the study conducted by Holly et al is used for sample size calculation.

$\mathrm{P}_{1}=22 \quad \mathrm{P}_{2}=75 \quad \mathrm{Z}=7.85 \quad \mathrm{n}=64$

Methodology: All patients posted for surgery will have a detailed preanaesthetic check up. Basal heart rate, systolic and diastolic blood pressure, oxygen saturation in room air are noted. Those who satisfy inclusion and exclusion criteria are selected and invited to take part in the study. Those who give informed consent will be 
randomly divided randomly into two groups using a computer generated random number table. GROUP-A - Those receiving intranasal dexmedetomidine (32 Patients) GROUP-B - Those receiving oral midazolam. (32 patients). Children are randomly allocated to one of the two groups. All children in Group A will receive intranasal dexmedetomidine $1 \mu \mathrm{g} / \mathrm{kg}$ and all children in group B will receive oral midazolam $0.5 \mathrm{mg} / \mathrm{kg}$, up to a maximum of $15 \mathrm{mg} . \mathrm{n}$ Intranasal dexmedetomidine is prepared from the $100 \mu \mathrm{g} / \mathrm{ml}$ parenteral preparation in a $1-\mathrm{ml}$ syringe, $0.9 \%$ saline is added to make a final volume of $0.4 \mathrm{ml}$. Alt study drugs are to be prepared and administ-ered by an independent anaesthesiogist who is not involved in the study. Observers and attending anesthesiaologists are blinded to the study drug given.

Children will have premedication in the preoperative holding area in the presence of one parent. Baseline heart rate (HR), oxygen saturation (Spo2), and blood pressure (BP) are measured before any drug administration Intranasal drug is dropped into both nostrils using a $1-\mathrm{ml}$ syringe with the child in the recumbent position.HR, Spo2 and BP are measured every 15 minutes until transfer to OR. Sedation status is assessed by a blinded observer every 15 minutes with a 6-point sedation scale, which is modified from the Observer Assessment of Alertness and Sedation Scale. Behavior is evaluated every 15 minutes with a 4-point behavior score. The duration of premedication is approximately 60 minutes; it can be longer or shorter depending on the schedule of the OR.

The primary outcomes measured are sedation score and behavior score on separation from parent and at induction. This is measured using the scoring system given below.

\section{Sedation scores}

1. Does not respond to mild prodding or shaking

2. Respond to mild prodding or shaking

3. Responds only after name is called loudly or repeatedly
4. Lethargic response to name spoken in normal tone

5. Appear lethargic but respond readily to name spoken in normal tone

6. Appear alert and awake, responds readily to name spoken in normal tone.

\section{Behavior scores}

1. Calm and cooperative

2. Anxious but reassurable

3. Anxious and not reassurable

4. Crying or resisting

\section{Wake-up behavior scores}

1. Calm and cooperative

2. Not calm but can be easily calmed

3. Not easily calmed, moderately agitated or restless

4. Combative, excited, disoriented

Mode of induction (IV versus inhalational) was decided by the attending anaesthesiologist. The airway was maintained with a face mask, endotracheal tube or laryngeal mask airway throughout the operation. Anaesthesia was maintained with isoflurane and $60 \%$ nitrous oxide in oxygen and muscle relaxant vecuronium as per the type of surgery. Regional anaesthesia was administered when-ever it was appropriate. When surgery was finished, the child was placed in the recovery position and allowed to wake up naturally in the post anaesthesia care unit (PACU). Behavior at awakening was evaluated with a fourpoint wake-up score. Time taken for readiness to be discharged from the PACU was recorded.

\section{Management of complications}

- Any episode of bradycardia is treated with injection Atropine $\quad 0.02 \mathrm{mg} / \mathrm{kg}$
intravenously.

- Hypotension is treated $0.9 \%$ normal saline infusion, intravenous ephedrine $3 \mathrm{mg}$ boluses.

\section{Outcome Measures}

The primary end-points were behavior and sedation status at separation from the parent and at induction of anaesthesia. Secondary endpoints 


\section{JMSCR Vol||05||Issue||02||Pages 17940-17950||February}

included systolic BP (SBP) and HR changes, wake-up behavior, and time, until ready for discharge from the PACU. Standard discharge criteria were used in the PACU. Patients were discharged from the PACU to the ward when they were awake, with reasonable control of pain and with vital signs within $20 \%$ of baseline values. Observations of sedation status and vital signs, including HR and Spo2, were made at $5 \mathrm{~min}$ and $\mathrm{BP}$ at $15 \mathrm{~min}$ intervals until the patient was ready to be discharged.

\section{Power Analysis}

In a previous study, about $70 \%$ of children demonstrated satisfactory sedation within $30 \mathrm{~min}$ of $0.5 \mathrm{mg} / \mathrm{kg}$ oral midazolam6; hence, a sample size of 96 (32 patients per group) provided 80\% power at 0.05 level of significance detect a $35 \%$ difference in the proportion of children who attain satisfactory sedation between oral midazolam and intranasal dexmedetomidine.

\section{Statistical Methods}

Sedation, behavior, and wake-up behavior scores were analyzed by Kruskal-Wallis test. When a significant result was obtained, the Mann-
Whitney $U$-test was applied for post hoc pair wise comparisons. Categorical data were analyzed by a-2 test. The adjusted $P$ value was applied to the post hoc pair wise comparisons for nonparametric and categorical data. The adjusted $P$ value for the 0.05 level of significance was 0.017 . Hemodynamic variables including $\mathrm{BP}$ and $\mathrm{HR}$ were analyzed by ANOVA. When a significant result was obtained, the Tukey test was applied for post hoc pair wise comparisons. The changes of BP and HR from baseline among the three groups were tested by Kruskal-Wallis Mest. The statistical software used was SPSS 15.0 for Windows (SPSS Inc., USA). For statistical analysis, sedation scores were categorized as being satisfactory when rated between 1 and 4 and unsatisfactory when rated 5 or 6 . Behavior scores and wake-up scores were categorized as satisfactory when they were 1 or 2 , and unsatisfactory when they were 3 or 4 .

\section{Observations and Results}

GROUP-A - Those receiving intranasal dexmedetomidine (32 patients)

GROUP-B - Those receiving oral midazolam. (32 patients)

Table 1. Patients' Demographic Data

\begin{tabular}{|l|c|c|c|}
\hline & Group B $(n-32)$ & Group A $(n-32)$ & P value \\
\hline Age $(\mathrm{yr}), \wedge /:$ & $6.4 \pm 3.0(2-12)$ & $6.1 \pm 2.7(2-12)$ & 0.615 \\
\hline Body weight $(\mathrm{kg})$ & $24.1+8.6$ & $21.6 \pm 5.8$ & 0.228 \\
\hline Sex, M:F & $30: 2$ & $30: 2$ & 0.857 \\
\hline Type of induction, gas: IV & $12: 20$ & $9: 23$ & 0.553 \\
\hline Type of surgery & \multicolumn{3}{|l|}{} \\
\hline High ligation hydrocele/orchidopexy & $2(6.3 \%)$ & $5(15.6 \%)$ & 0.657 \\
\hline $\begin{array}{l}\text { Excision lymph nodes or lumps } \\
\text { Circumcision/other penile surgery ; }\end{array}$ & $6(18.8 \%)$ & $3(9.4 \%)$ & \\
\hline Cystoscopy/colonoscopy/EUA & $4(12.5 \%)$ & $3(9.4 \%)$ & 0.117 \\
\hline $\begin{array}{l}\text { Duration of surgery (min) } \\
\text { Time from premedication to induction } \\
\text { (min) }\end{array}$ & $27.7 \pm 10.1(10-50)$ & $33.4 \pm 14.1(15-85)$ & 0.180 \\
\hline
\end{tabular}

EUA examination under anaesthesia

Demographic characteristics for all patients are summarized in Table 1. Patients in the two groups were comparable with respect to age, weight, gender, type of surgery, duration of surgery, and type of induction. Two of 32 children resisted intranasal drug administration and 1 of 32 resisted oral medications. No child complained of pain or discomfort with intranasal drug administration. The children who resisted the medication were also included in the analysis. 


\section{JMSCR Vol||05||Issue||02||Pages 17940-17950||February}

Assessment of Sedation and Behavior at Separation and at Induction. The median sedation scores at separation from the parent were 6 and 1.5 for groups B and A respectively. The sedation scores of children from group A were significantly different from that of group B at separation from parents $(P-0.0 \mathrm{G} 1$ and -0.001$)$. Moreover, 21.9\% and $75 \%$ of the children from groups $\mathrm{B}$ and $\mathrm{A}$ achieved satisfactory sedation at separation from parents. There were significantly more children in group A who achieved satisfactory sedation $h$ when compared with group B $(P-0.002$ and 0.001 , respectively) (Table 1 ). The median sedation scores at induction were 6 and 4 for groups B and A respectively. Group A patients were significantly more sedated than group $B$ at induction of anaesthesia $(P-0.009)$.

At induction of anaesthesia, $18.8 \%$ and $53.1 \%$ of the children from groups B and A respectively, were satisfactorily sedated. Significantly more children from group A achieved satisfactory sedation when compared with group B ( $P$ - 0.004) (Table 2); There was no evidence found for a difference in behavior scores at separation from parents and at induction of anaesthesia among the two groups. All children except one in group B had satisfactory behavior at separation from parents $(P$ - 0.771) (Table 2).

Most children had satisfactory behavior at induction of anaesthesia with no evidence of a difference among groups (P-0.148) (Table 2). The proportion of children who had satisfactory behavior at separation from parents, but became distressed at induction of anaesthesia, were $0 \%$, and $18.8 \%$ from groups B and A respectively.

Although there was a tendency for more children who had received dexmedetomidine to develop unsatisfactory behavior at induction of anaesthesia, and the $P$ value from $\mathrm{X}^{2}$ test was 0.012 , post hoc pair wise comparisons did not reveal any significant difference among the two groups. Of the children from groups $\mathrm{B}$ and $\mathrm{A}$ respectively, $14.3 \%$ and $29.2 \%$ were awoken by the transfer from the preoperative holding area to the OR. There was a tendency for more children who had received dexmedetomidine to awaken during this transfer, although these differences were not statistically significant (P -0.828) (Table 2)

Table 2. Distribution of Behavior and Sedation Status at Parental Separation and at Induction, Proportion of Children Who Had Change of Behavior and Sedation from Satisfactory to Unsatisfactory at Induction, Time Ready for Discharge from Post anesthetic Care Unit (Minutes)

\begin{tabular}{|c|c|c|c|}
\hline \multicolumn{4}{|l|}{ Successful parental separation } \\
\hline Yes & $31(96.9 \%)$ & $32(100 \%)$ & 0.771 \\
\hline NO & $1(3.1 \%)$ & 0 & \\
\hline \multicolumn{4}{|l|}{ Sedation at separation from parent } \\
\hline Satisfactory & $7(21.9 \%)$ & $24(75 \%)$ & $\wedge 001 *$ \\
\hline Unsatisfactory & $25(78.1 \%)$ & $8(25 \%)$ & \\
\hline \multicolumn{4}{|l|}{ Behavior at induction } \\
\hline Satisfactory & $31(96.9 \%)$ & $26(81.3 \%)$ & 0.148 \\
\hline Unsatisfactory & $1(3.1 \%)$ & $6(18.8 \%)$ & \\
\hline \multicolumn{4}{|l|}{ Sedation at induction } \\
\hline Satisfactory & $6(18.8 \%)$ & $17(53.1 \%)$ & $0.016^{*}$ \\
\hline Unsatisfactory & $26(81.3 \%)$ & $15(46.9 \%)$ & \\
\hline $\begin{array}{l}\text { Change of behavior at induction from } \\
\text { satisfactory to unsatisfactory } / \mathrm{i} / \text { total }(\%)\end{array}$ & $0 / 31(0)$ & $\begin{array}{c}6 / 32 \\
(18.8 \%)\end{array}$ & 0.012 \\
\hline $\begin{array}{l}\text { Change of sedation at induction from } \\
\text { Satisfactory to Unsatisfactory n/total }(\%)\end{array}$ & $1 / 7(14.3)$ & $7 / 24(29.2)$ & 0.828 \\
\hline
\end{tabular}




\section{JMSCR Vol||05||Issue||02||Pages 17940-17950||February}

Significant different between Group B and Group $\mathrm{A}$ at 0.05 level. The median behavior score and sedation score were further analyzed with the children divided into three different age groups, age $<6$, age 6-9, and age 10-12yr. The median behavior scores at baseline, at separation from parent, and at induction were not different among the children from groups $\mathrm{B}$ and $\mathrm{A}$ in all age groups. The median sedation scores of group $\mathrm{A}$ was significantly different from that of group B at separation from parent and at induction in children of age $<6 \mathrm{yr}$ (Table 3 ). In age Group $<6 \mathrm{yr}$, the median sedation scores at separation from parent were 6 and 2 group B and A respectively ( $P<$ $0.001)$. For the same age group, the median sedation scores at induction of anaesthesia. Were 6 and 2 for group B and A respectively $(P<$ 0.001). These differences were not observed in older children (Table 3 ).

Table 3. Sedation Scores in Different Age Groups

\begin{tabular}{|l|c|c|c|}
\hline & Group B & Group A & P value \\
\hline Age <6yrs & & & \\
\hline Baseline & $6(6-6)$ & $6(6-6)$ & 0.393 \\
\hline Separation from & $6(6-6)$ & $1(1-2)$ & $<0.001$ \\
\hline parent & $6(6-6)$ & $2(2-6)$ & $<0.001^{*}$ \\
\hline At induction & & & \\
\hline Age 6 -9 yrs & & & 0.287 \\
\hline Baseline $f$ & $6(6-6)$ & $6(6-6)$ & 0.122 \\
\hline Separation from & $5.5(4.75-6)$ & $2(1-6)$ & 0.691 \\
\hline parent j & $6(5-6)$ & $6(3-6)$ & \\
\hline At induction & & & 1.000 \\
\hline Age 10-12yrs & & & 0.112 \\
\hline Baseline 1 & $6(6-6)$ & $6(6-6)$ & 0.525 \\
\hline Separation from & $6(1-6)$ & $2(1.25-2)$ & \\
\hline parent & $6(1-6)$ & $4.5(2.5-5.75)$ & \\
\hline At induction & & & \\
\hline
\end{tabular}

Values in median_IQR Respiratory and Hemodynamic Effects. Overall, we did not observe any clinically significant effects of the study drugs on Spo2 and no child had a reduction of Spo2 to below 95\% during the observation period after premedication. Only children who stayed for more than 60 min after premedication were included in the analysis of SBP and HR during the premedication period by repeated measures of ANOVA. Consequently 25 and 18 children from groups B and A, respectively were included in this analysis. There were significant group and time effects on SBP $(P=0.025$ and $<0.001$, respectively). There was no significant group $\mathrm{x}$ time interaction $(P=0.085)$. Post hoc analysis showed that SBP decreased significantly in group A when compared with group B $(P=$
0.004). Moreover, SBP decreased with time and it was significantly different from baseline at $30 \mathrm{~min}$ $(P=0.003), 45 \mathrm{~min}(P=0.001)$, and $60 \mathrm{~min}(P=$ $0.001)$ after drug administration in group $A$. The SBP was reduced by $14.1 \%$ at $60 \mathrm{~min}$ in group A. There was also a significant time effect on HR $(P$ $=0.001)$ and group time interaction $\mid(P=0.001)$. The group effect on HR was not significant $(P=$ $0.102^{\wedge}$. Post hoc analysis showed that HR decreased significantly with time in group $A(P=$ $0.001)$. The HR became significantly reduced from baseline at 45 and $60 \mathrm{~min}$ after drug administration in group A $(P=0.006$ and $<0.001$, respectively). The HR became significantly reduced from baseline at 45 and 60 min after drug administration in group $\mathrm{A}(\mathrm{P}=0.001)$. 
Discussion

Sedative and Anxiolytic Effects: This prospective, randomized, controlled trial compared intranasal dexmedetomidine and oral midazolam as premedication in healthy children Between 4 and 12-yr-of-age. Children premedicated with $1 \mu \mathrm{g} / \mathrm{kg}$ of intranasal dexmedetomidine attained more significant and satisfactory sedation at parental separation and at induction of anaesthesia than those patients who received oral midazolam. Other studies showed that patients premedicated with $0.5 \mu \mathrm{g} / \mathrm{kg}$ dexmedetomidine were initially effectively sedated; these children were aroused more easily with external stimulation. Hence, the $0.5 \mu \mathrm{g} / \mathrm{kg}$ dose may not be adequate for children. Most children tolerated the intranasal and oral study drugs.

Previous studies have shown that intranasal administration is an effective way to administer premedication and sedation to children (23-25). It is a relatively easy and noninvasive route with a high bioavailability. However, cooperation is still required and it may be more difficult in younger children. Oral administration may be even more difficult in uncooperative children. Unlike conventional gabaminergic sedative drugs, such as midazolam, dexmedetomidine's site of action in the central nervous system is primarily in the locus coeruleus where it induces electroencephalogram activity similar to natural sleep. It is, therefore, not surprising that external stimulation should facilitate arousal. Patients are also less likely to become disorientated and uncooperative. A recent study has demonstrated that $75 \%$ and $92 \%$ of adult healthy volunteers attained significant sedation after 1 and $1.5 \mu \mathrm{g} / \mathrm{kg}$ intranasal dexmedetomidine, respectively. In this investigation, we have shown that $75 \%$ of the children attained a satisfactory level of sedation after $1 \mathrm{ng} / \mathrm{kg}$ intranasal dexmedetomidine. Moreover, $70.8 \%$ of these sedated patients allowed IV or inhaled induction without showing signs of distress or awakening. The doses of 0.5 and $1 \mu \mathrm{g} / \mathrm{kg}$ intranasal dexmedetomidine were chosen in this preliminary investigation in order to evaluate the lowest effective dose. Although 0.5 $\boldsymbol{\mu} \mathrm{g} / \mathrm{kg}$ intranasal dexmedetomidine produced effective sedation at parental separation, it was not effective when the children were transferred to the OR* Subgroup analysis revealed that children from age group $<6 \mathrm{yr}$ seemed to be more sedated with intranasal dexmedetomidine. However, the lack of a significant sedative effect of intranasal dexmedetomidine in age groups 6-9 and 10-12 could be real or due to an inadequate sample size. Since this study was not designed to investigate the sedative effect of intranasal dexmedetomidine in different age groups, we cannot draw a conclusion on this. Future studies- could address the sedative effect of intranasal dexmedetomidine on children of varying ages. The reported sedative effects of midazolam are quite variable. Effective sedation has been reported to range from $39 \%$ to 75\% 27-30 when a parenteral preparation was used for oral administration. In two different studies, commercially prepared oral midazolam has been shown to produce satisfactory sedation in $97 \%$ and $81 \%$ of clfildren.5,9 Our study has shown that only $21.9 \%$ of children receiving $0.5 \mathrm{mg} / \mathrm{kg}$ of oral midazolam were sedated. The great variability may be due to a difference in study design, different carrier vehicle for midazolam, and different bioavailabities of the midazolam preparation. Although previous studies have documented the effectiveness of oral midazolam as a preoperative anxiolytic,3,4,10,30-32 our behavior scoring system did not allow us to evaluate the anxiety level of children.

We have shown in this investigation that the behavior of children at separation -from parents and at induction of anaesthesia were similar in children who received oral midazolam and intranasal dexmedetomidine based on our behavior scale. Although oral midazolam did not produce significant sedation in our subjects, it could have produced significant anxiolytic and/or amnesic effects. It is also uncertain if the sedative effect of intranasal dexmedetomidine is associated with any anxiolytic effect. The use of other validated anxiety scales such as the modified Yale 
Preoperative Anxiety Scale would allow evaluation of the change in anxiety level of children after premedication and to delineate the sedative effect from anxiolytic effect. Hemodynamic Effects a2-Agonists produce a modest reduction in $\mathrm{BP}$ and $\mathrm{HR}$. When dexmedetomidine is infused as an IV bolus at doses ranging from 0.25 to $2 \mu \mathrm{g} / \mathrm{kg}$ over $2 \mathrm{~min}$ in healthy volunteers, 34 it causes a dose-dependent decrease in BP ranging from $14 \%$ to $27 \%$. When clonidine was given as premedication, it was shown to effectively attenuate the cardiovascular responses to tracheal intubation in children undergoing induction of anaesthesia. In a recent study comparing midazolam, clonidine, and dexmedetomidine for premedication in children, both clonidine and dexmedetomidine were shown to reduce mean BP and HR before and during surgery. 17 In a pharmacokinetic study of IV dexmedetomidine in children, it was shown that 0.66 and $1 \mathrm{ng} / \mathrm{kg}$ IV dexmedetomidine given over $10 \mathrm{~min}$ produced a significant reduction of $\mathrm{HR}$ $(<15 \%$ compared with baseline) and SBP $(<25 \%$ compared with baseline). Munro et al. reported that the reduction of blood pressure and HR were $<20 \%$ of baseline in children who were sedated with an initial dose of $\quad \begin{array}{lllll}\mu \mathrm{g} & / \mathrm{kg} & \text { IV }\end{array}$ dexmedetomidine, followed by a maintenance infusion during cardiac catheterization. In this study, we have shown that preoperative 0.5 and 1 $\boldsymbol{\mu} \mathrm{g} / \mathrm{kg}$ intranasal dexmedetomidine reduces HR and blood pressure in healthy children during the first hour after drug administration.

\section{Limitations of this Study}

We did not evaluate the onset time and peak effect of the two doses of intrafiasal dexmedetomidine or the blood concentrations. The onset time of 1 $\mathrm{ng} / \mathrm{kg}$ intranasal dexmedetomidine was about 45 min with a peak effect at 60- 105 |min after intranasal dexmedetomidine in healthy adults. In this study, the premedication period was $60 \mathrm{~min}$ for intranasal dexmedetomidine; however, some children were transferred to the OR slightly earlier in order not to interfere with the normal OR schedule. If a longer premedication period had been allowed, possibly more subjects could have attained satisfactory sedation at separation from parents and at induction of anaesthesia. The sedation produced by dexmedetomidine differs from other sedatives as patients may be easily aroused and cooperative. Some children who were premedicated with dexmedetomidine became distressed when they were aroused at the induction of anaesthesia, despite being very much sedated at the time of parental separation. Anaesthetic technique may need to be adjusted to provide optimal conditions for induction in children sedated with dexmedetomidine.

\section{Conclusion}

Although midazolam is the most commonly used premedication in children, it may not be the most suitable preoperative sedative and anxiolytic in all children and in all circumstances. Finley et al. ${ }^{(37)}$ have shown that children with impulsive traits did not benefit from midazolam premedication. In this study, we have shown that $1 \mathrm{ng} / \mathrm{kg}$ intranasal dexmedetomidine is another technique for producing sedation in children and it causes no discomfort during administration. Intranasal drug administration is relatively quick, simple, and may have benefits over transmucosal routes or rectal administration, which requires more patient cooperation. We have established that this route is feasible for dexmedetomidine administration and future studies could now be directed to further evaluate the effect of this interesting drug on various outcome measures including preoperative anxiety levels, induction time, emergence excitation, postoperative analgesic requirements, and postoperative behavior disturbances. In summary, $1 \mu \mathrm{g} / \mathrm{kg}$ intranasal dexmedetomidine produces significant sedation in children between 4 and 12-yr-of-agi. Behavior of the children at parental separation and at induction of anaesthesia was comparable to children who received oral midazolam. The hemodynamic effects of the intranasal dexmedetomidine were modest 


\section{Bibliography}

1. Kain ZN, Caldwell-Andrews AA, Krivutza DM, Weinberg ME, Wang S-M, Gaal D. Trends in the practice of parental presence during induction of anaesthesia and the use of preoperative sedative premedication in the United States, 1995-2002: results of a follow-up I national survey. Anesth Analg 2004;98:1252-9.

2. Kain ZN, Mayes L, Bell C, Weisman S, Hofstadter M, Rimar S. Premedication in the United States: a status report. Anesth Analg 1997;84:427-32.

3. Kain ZN, Mayes LC, Wang SM, Caramico LA, Hofstadter MB. Parental presence during induction of anaesthesia versus sedative premedication: which intervention is more effective? Anesthesiology 1998;89:1147-56.

4. Kain ZN, Hofstadter MB, Mayes LC, Krivutza DM, Alexander G, Waqjg SM, Reznick JS. Midazolam: effects on amnesia and anxiety in children. Anesthesiology 2000;93:676-84.

5. Cote CJ, Cohen IT, Suresh S, Rabb M, Rose JB, Weldon C, Davis PJ, Bikhazi GB, Karl HW, Hummer KA, Hannallah RS, Khoo KC, Collins P. A comparison of three doses of commercially prepared oral midazolam syrup in children. Anesth Analg 2002;94:37-43

6. Kogan A, Katz J, E-frat R, Eidelman LA. Premedication with midazolam in young children: a comparison of four routes of administration. Paediatr Anaesth 2002; 12:685-9.

7. Splinter WM, MacNeill HB, Menard EA, Rhine EJ, Roberts DJ, Gould MH. Midazolam reduces vomiting after tonsillectomy in children. Can J Anaesth 1995;42:201-3.

8. Buffett-Jerrott SE, Stewart SH, Finley GA, Loughlan HL. Effects of benzodiazepines on explicit memory in a pediatric surgery setting. Psychopharmacology (Berl) 2003;168:377-86.
9. Marshall J, Rodarte A, Blumer J, Khoo KC, Akbari B, Kearns G. Pediatric pharmacodynamics of midazolam oral syrup. Pediatric Pharmacology Research Unit Network. J Clin Pharmacol 2000;40: 578-89.

10. Cox RG, Nemish U, Ewen A, Crowe M-J. Evidence-based clinical update: does premedication with oral midazolam lead to improved behavioral outcomes in children? Can J Anaesth 2006;53:1213-19.

11. Khalil S, Vije H, Kee S. A pediatric trial comparing midazolam/syrpalta mixture with premixed midazolam syrup (Roche). Paediatr Anaesth 2003;13:205-9

12. Lonnqvist PA, Habre W. Midazolam as premedication: is the emperor naked or just half-dressed? Paediatr Anaesth 2005; 15: 263-5

13. Kanegaye JT, Favela JL, Acosta M, Bank DE. High-dose rectal midazolam for pediatric procedures: a randomized trial of sedative efficacy and agitation. Pediatr Emerg Care 2003;19:329-36.

14. McGraw T, Kendrick A. Oral midazolam premedication and I postoperative behavior in children. Paediatr Anaesth 1998;8:117-21.

15. Watson AT, Visram A. Children's preoperative anxiety and postoperative behavior. Paediatr Anaesth 2003;13:18820416.

16. Bergendahl H, Lonnqvist P-A, Eksborg S. Clonidine in pediatric anaesthesia: a review of the literature and comparison with benzodiazepines for premedication. Acta Anaesthesiol Scand 2006;50:135-43

17. Schhiidt AP, Valinetti EA, Banderira D, Bertacchi MF, Simoes CM, JOSjE OTAVIO C Auler, JR. Effects of preanesthetic administration of midazolam, clonidine, or dexmedetomidine on postoperative pain and anxiety in children. Paediatr Anaesth 2007; 17:667-74. 
18. Mikawa K, Maekawa N, Nishina K, Takao Y, Yaku H, Obara H. Efficacy of oral clonidine premedication in children. Anesthesiology 1993;79:926-31

19. Ramesh VJ, Bhardwaj N, Batra YK. Comparative study of oral clonidine and diazepam as premedicants in children. Int $\mathbf{J}$ Clin Pharmacol Ther 1997;35:218-21.

20. Tazeroualti N, De Groote F, De Hert S, De Ville A, Dierick A, Van der Linden P. Oral clonidine vs midazolam in the prevention of sevoflurane-induced agitation in children. A prospective, randomized, controlled trial. Br J Anaesth 2007;98:667-71

21. Anttila M, Penttila J, Helminen A, Vuorilehto L, Scheinin H. Bioavailability of dexmedetomidine after extravascular doses in healthy subjects. $\mathrm{Br} \mathrm{J}$ Clin Pharmacol 2003;56:691-3.

22. Yuen VM, Hui TW, Yuen MK, Irwin MG. A double blind crossover assessment of the sedative and analgesic effects of intranasal dexmedetomidine. Anesth Analg 2007;105:374-80

23. Weber F, Wulf H, el Saeidi G. Premedication with nasal s-ketamine and midazolam provides good conditions for induction of anaesthesia in pleschool children. Can J Anaesth 2003;50:470-5

24. Alinkin JL, Fazi LM, Cuy RM, Chiavacci RM, Kurth CD, Shah UK, Jacobs IN, Watcha MF. Use of intranasal fentanyl in children undergoing myringotomy and tube placement during halothane and sevoflurane anaesthesia. Anesthesiology 2000;93: 1378-83

25. Almenrader N, Passariello M, Coccetti B, Haiberger R, Pietropaoli P. Steal-induction after clonidine premedication: a comparison of the oral and nasal route. Paediatr Anaesth 2007;17:230-4.

26. Khan ZP, Ferguson CN, Jones RM. alpha2 and imidazoline receptor agonists. Their pharmacology and therapeutic role. Anaesthesia 1999;54:146-65.
27. Ghai B, Grandhe RP, Kumar A, Chari P. Comparative evaluation of midazolam and ketamine with midazolam alone as oral premedication. Paediatr Anaesth 2005;15:554-9

28. Darlong V, Shende D, Subramanyam MS, Sunder R, Naik A. Oral ketamine or midazolam or low dose combination for premedication in children. Anaesth Intensive Care 2004;32:246-9.

29. Horiuchi T, Kawaguchi M, Kurehara K, Kawaraguchi Y, Sasaoka N, Furuya H. Evaluation of relatively low dose of oral transmucosal ketalnine premedication in children: a comparison with oral mid|zolam. Paediatr Anaesth 2005;15:643-7.

30. McMillan CO, Spahr-Schopfer IA, Sikich N, Hartley E, Lerman J. Premedication of children with oral midazolam. Can J Anaesth 1992;39:545-50.

31. Feld LH, Negus JB, White PF. Oral midazolam preanesthetic medication in pediatric outpatients. Anesthesiology 1990;73:831-4. Samarkandi A, Naguib M, Riad W, Thalaj A, Alotibi W, Aldammas F, Albassam A. Melatonin vs. midazolam premedication in children: a double-blind, placebo-controlled study. Eur J Anaesthesiol 2005;22:189-96.

32. Kain ZN, Mayes LC, Cicchetti DV, Bagnall AL, Finley JD, Hofstadter MB. The Yale Preoperative Anxiety Scale: how does it compare with a "gold standard"? Anesth Analg 1997;85:783-8.

33. Bloor B, Ward D, Belleville J, Maze M. Effects of intravenous dexmedetomidine in humans. II. Hemodynamic changes. Anesthesiology 1992;77:1134-42.

34. Petroz GC, Sikich N, James M, van Dyk H, Shafer SL, Schily M, Lerman J. A phase I, two-center study of the pharmacokinetics and of dexmedetomidine in children. Anesthesiology

35. Munro HM, Tirotta CF, Felix DE, Lagueruela RG, Madril DR, Zahn EM, 
Nykanen DG. Initial experience with dexmedetomidine for diagnostic and interventional cardiac catheterization in children. Paediatr Anaesth 2007; 17:10912.

36. Finley GA, Stewart SH, Buffett-Jerrott S, Wright KD, Millington D. High levels of impulsivity may contraindicate midazolam premedication in children. Can J Anaesth 2006;53:73-8

37. Peeters MY, Prins SA, Knibbe CA, DeJongh J, van Schaik RH, van Dijk M, et al. Propofol pharmacokinetics and pharmacodynamics for depth of sedation in nonventilated infants after major craniofacial surgery. Anesthesiology. 2006;104(3):466-74.

38. Civantos Calzada B, Aleixandre de Artinano A. Alpha-adrenoceptor subtypes. Pharmacological Research. 2001;44(3): 195-208.

39. Ahlquist RP. A study of the adrenotropic receptors. Am J Physiol. 1948;153(3):586600.

40. Laner SZ. Presynaptic regulation of cathecolamine release. Biochemical Pharmacology. 1974;23:1793-800.

41. Schimmel RJ. Roles of alpha and beta adrenergic receptors in control of glucose oxidation in hamster epididymal adipocytes. Biochimica et If Biophysical Acta. 1976;428(2):379-87.

42. Berthelsen S, Pettinger WA. A functional basis for classification of alpha-adrenergic receptors. Life Sciences. 1977;21(5):595606.

43. Drew GM, Whiting SB. Evidence for two distinct types of postsynaptic alphaadrenoceptor in vascular smooth muscle in vivo. Br J Pharmacol. 1979;67(2):207-15.

44. Bylund DB. Heterogeneity of alpha-2 adrenergic receptors. Pharmacology, Biochemistry \& Behavior. 1985;22(5): 835-43. 